\title{
Spectroscopic Investigations of Pentobarbital Interaction with Transthyretin
}

\author{
Saqer M. Darwish, ${ }^{1}$ Jafar Ghithan, ${ }^{1}$ Musa M. Abuteir, ${ }^{1}$ \\ Mariam Faroun, ${ }^{2}$ and Mahmoud M. Abu-hadid ${ }^{3}$ \\ ${ }^{1}$ Department of Physics, Al-Quds University, P.O. Box 20002, Abu Dies, Jerusalem, Israel \\ ${ }^{2}$ Nanotechnology Center, Al-Quds University, P.O. Box 20002, Abu Dies, Jerusalem, Israel \\ ${ }^{3}$ Department of Immunology, Al-Quds University, P.O. Box 20002, Abu Dies, Jerusalem, Israel
}

Correspondence should be addressed to Saqer M. Darwish; sdarwish@science.alquds.edu

Received 27 June 2012; Accepted 9 October 2012

Academic Editor: Piotr Przybylski

Copyright (C) 2013 Saqer M. Darwish et al. This is an open access article distributed under the Creative Commons Attribution License, which permits unrestricted use, distribution, and reproduction in any medium, provided the original work is properly cited.

Transthyretin (TTR) aggregation has been characterized to be responsible for several amyloid diseases. Fourier transform infrared (FTIR) spectroscopy, fluorescence, and atomic force microscopy (AFM) are used to investigate secondary structure changes in transthyretin, induced upon thermal denaturation and interaction with pentobarbital. Spectral analysis revealed a strong static quenching of the intrinsic fluorescence of TTR by pentobarbital with a binding constant (K) estimated at $2.092 \times 10^{3} \mathrm{M}^{-1}$. Fourier self-deconvolution (FSD) technique is used to evaluates intensity changes in the spectra of the component bands in the amide I and amide II regions due to the changes in pentobarbital concentration in the protein complex. The increases of the relative intensities of the peaks at $1614 \mathrm{~cm}^{-1}$ and $1507 \mathrm{~cm}^{-1}$ are due to the increase of pentobarbital concentrations which is linked to the formation of oligomers in the protein.

\section{Introduction}

Transthyretin (TTR) is a plasma protein composed of $127-$ residue subunits mainly composed of $\beta$-sheet structures [1]. It is present in both human plasma and cerebrospinal fluid (CSF) with concentrations of $(0.1-0.4 \mathrm{mg} / \mathrm{mL})$ in human plasma and $(0.017 \mathrm{mg} / \mathrm{mL})$ in CSF [2]. X-ray crystal structure studies have shown that human TTR have a molecular weight of $55 \mathrm{kDa}$ in a tetramer form with four identical subunits [3].

TTR is synthesized by the liver and released in the plasma, while the TTR in CSF is mostly produced by the choroid plexus [4-6]. It is considered to be the primary transporter of thyroid hormones in the form of thyroxine in the CSF and it carries retinol via interaction with the retinol-binding protein (RBP) [7].

Other additional function of TTR has been detected in the development of the central nervous system due to the high concentration during the prenatal and postnatal life [8]. Several research groups have shown cerebral TTR expression to rise during the course of experimental Alzheimer disease
(AD) in mice and in response to the intake of some drug or mixtures of compounds such as gingko extracts or dietary fatty acids $[9-11]$.

The process of transthyretin amyloidogenesis or amyloid fibril formation seems to be associated with some amyloid diseases. It is not understood precisely how TTR forms amyloids, but several biophysical studies on wild-type (WT) TTR reveals that tetramer dissociation is rate limiting for amyloidogenesis [12-14]. All amyloid diseases are characterized by misfolded proteins that undergo aggregation causing a deposition of insoluble amyloid fibrils either systemically or in specific organs as the brain [15-18]. It is believed that such disorders can lead to several diseases such as in familial amyloid polyneuropathy, Alzheimer, Parkinson's, Huntington's, and type II diabetes [15, 19-23]. Familial amyloid polyneurophy and senile systematic amyloidosis are two diseases associated with formation of TTR fibrils due to the lack of stability in parallel $\beta$-sheets. The precise mechanisms of TTR amyloid fibril formations at the molecular level are not known, Quintas et al. suggested that amyloid 
fibril formation might be triggered by tetramer dissociation to a compact nonnative monomer with low-conformational stability, which results in partially unfolded monomeric species with a high tendency for ordered aggregation into amyloid fibrils [24].

Although understanding the mechanisms of protein aggregation is remained to be a very crucial issue, current research supports the notion that small toxic oligomers are formed during the aggregation results in cellular dysfunction and death $[20,21]$.

Recent studies suggest that neurodegenerative disorders, such as Alzheimer's and Parkinson's diseases, might be accelerated by the intake of anesthetic drugs [25-28]. It is been suggested that some small ligands can bind strongly to wild-type TTR forming a stable folded state leading to an amoloid formation $[29,30]$. The commonly used inhalation anesthetic isoflurane has been reported to induce apoptosis, which, in turn, increases aggregation of amyloid $\beta$-protein in cultured cells [28].

Infrared (IR) spectroscopy is one of the oldest and well-established experimental techniques for the analysis of secondary structure of polypeptides and proteins [31-34]. FTIR spectroscopy revealed that certain vibration-frequency bands can be used to follow the aggregation and to explore environmental properties and temperature effects on the structure of proteins [24]. The presence of $\beta$-sheets in the core of amyloid fibrils focused the investigations to $\beta$-sheet containing proteins such as transthyretin to find if such proteins are predisposed to form such fibrils. However, any differences in the molecular structure of the protein can be detected from the changes in the amide I region of the infrared spectrum by measuring changes in the intensities of the absorption bands of $\beta$-sheets [34].

In this work we investigated possible changes in the intensity of the component bands of the secondary structure by changing temperatures and concentrations of pentobarbital in the protein complexes. The binding of pentobarbital to TTR was investigated by means of Fluorescence and FTIR spectroscopy. In addition we used atomic force microscopy (AFM) to monitor physical changes of the molecular structure of the complex-protein $[35,36]$.

\section{Materials and Methods}

Pentobarbital in salt form with chemical structure shown in Figure 1, and transthyretin in Lyophilized powder were purchased from Sigma Aldrich chemical company and used without further purification.

2.1. Preparation of Stock Solutions. TTR was dissolved in $99.9 \% \mathrm{D}_{2} \mathrm{O}$ at a concentration of $5 \mathrm{mg} / \mathrm{mL}$ in $10 \mathrm{mM}$ phosphate buffer saline at physiological $\mathrm{pH}$ 7.4. Pentobarbital with molecular weight of $(226.3 \mathrm{~g} / \mathrm{moL})$ was dissolved in $99.9 \%$ $\mathrm{D}_{2} \mathrm{O}$ and $10 \mathrm{mM}$ phosphate buffer saline to attain the desired drug concentration of $15.36 \mathrm{mM}$.

In the final step drug solution was added to an equal volume of the protein solution to attain the desired pentobarbital

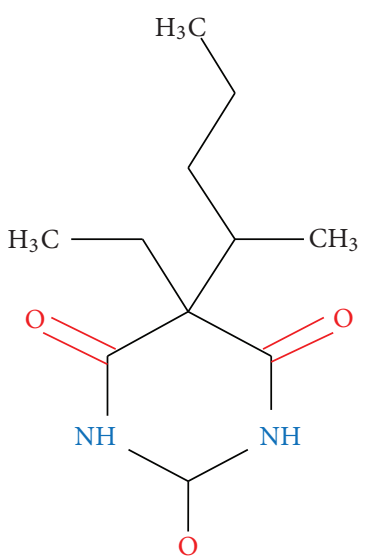

FIGURE 1: Chemical structure of pentobarbital.

concentrations of $7.68,3.84,1.92$, and $0.96 \mathrm{mM}$ with a final protein concentration of $2.5 \mathrm{mg} / \mathrm{mL}$.

2.2. Fluorescence Spectroscopy. The fluorescence measurements were performed by a NanoDrop ND-3300 Fluorospectrometer at $25^{\circ} \mathrm{C}$. The excitation source comes from one of three solid-state light emitting diodes (LED's). The excitation source options include UV LED with maximum excitation $365 \mathrm{~nm}$, Blue LED with excitation $470 \mathrm{~nm}$, and white LED from 500 to $650 \mathrm{~nm}$ excitation. A 2048-element CCD array detector covering $400-750 \mathrm{~nm}$ is connected by an optical fiber to the optical measurement surface. The excitation is done on the wavelength of $360 \mathrm{~nm}$ and the maximum emission wavelength is at $423 \mathrm{~nm}$.

2.3. FTIR Spectroscopic Measurements. FTIR measurements were obtained on a Bruker IFS 66/S spectrophotometer equipped with liquid nitrogen cooled MCT detector and a $\mathrm{KBr}$ beam splitter. The spectrometer was continuously purged with dry air during the measurements. Samples are prepared after $2 \mathrm{~h}$ of incubation of TTR with pentobarbital solution at room temperature, $50 \mu \mathrm{L}$ of the sample were placed on a certain area on a silicon window plate and left to dry at room temperature inside an incubator. The dehydrated films are made with desired concentrations of pentobarbital while keeping the same protein content.

The absorption spectrum were recorded in mid-infrared range (4000-400 $\mathrm{cm}^{-1}$ ), as an average of 60 scans to increase the signal to noise ratio, and the spectral resolution was at $4 \mathrm{~cm}^{-1}$. The aperture used in this study was $8 \mathrm{~mm}$, since we found that this aperture gives the best signal to noise ratio. Baseline correction and normalization were performed for all the spectra by OPUS software.

For the temperature dependence studies, proteinpentobarbital complexes on silicon windows were placed into an infrared cell window. The temperature in the cell was controlled by an external water path and was increased gradually between $20^{\circ} \mathrm{C}$ and $80^{\circ} \mathrm{C}$ at $3^{\circ} \mathrm{C}$ per 10 minute scan rate. 


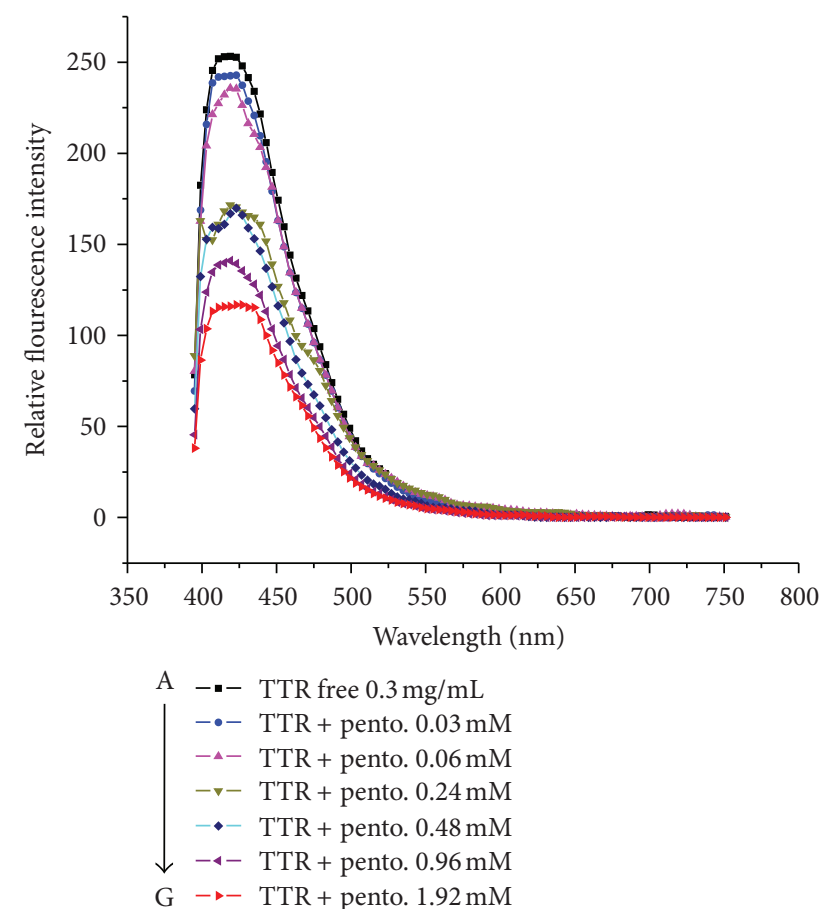

FIGURE 2: Fluorescence emission spectra of TTR pentobarbital complexes at different pentobarbital concentrations.

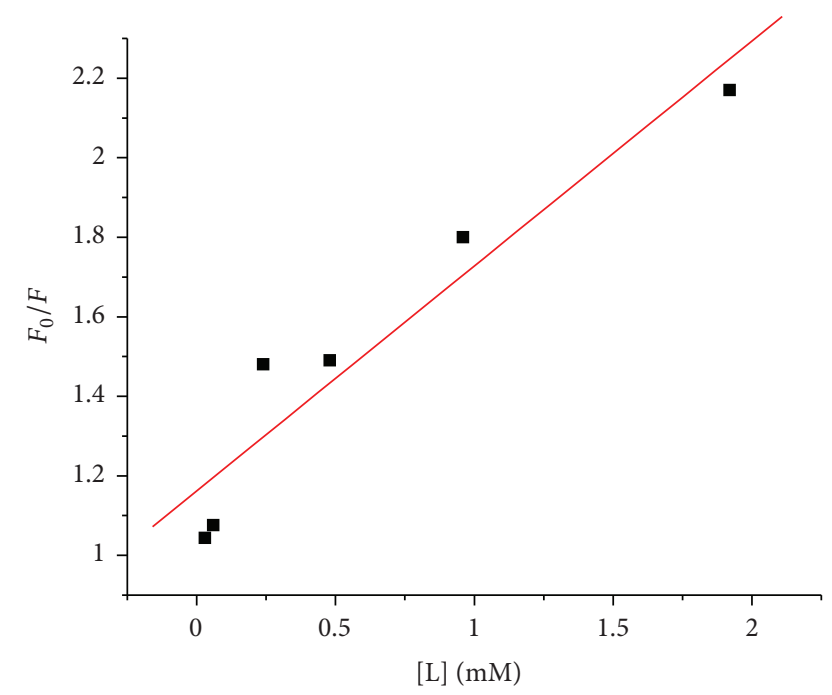

FIGURE 3: The Stern-Volmer plot for pentobarbital-TTR complexes.

Peak positions were determined using the second derivative by OPUS software. Calculations of the areas under the different curves were performed using FSD techniques by OPUS software.

2.4. AFM Measurements. The prepared stock solutions of pentobarbital-TTR complex are incubated for $2 \mathrm{~h}$ at room temperature. A $10 \mu \mathrm{L}$ of the solution is placed on certain area of a freshly cleaved mica substrate and left to dry at room temperature. TTR free and TTR-pentobarbital solutions were

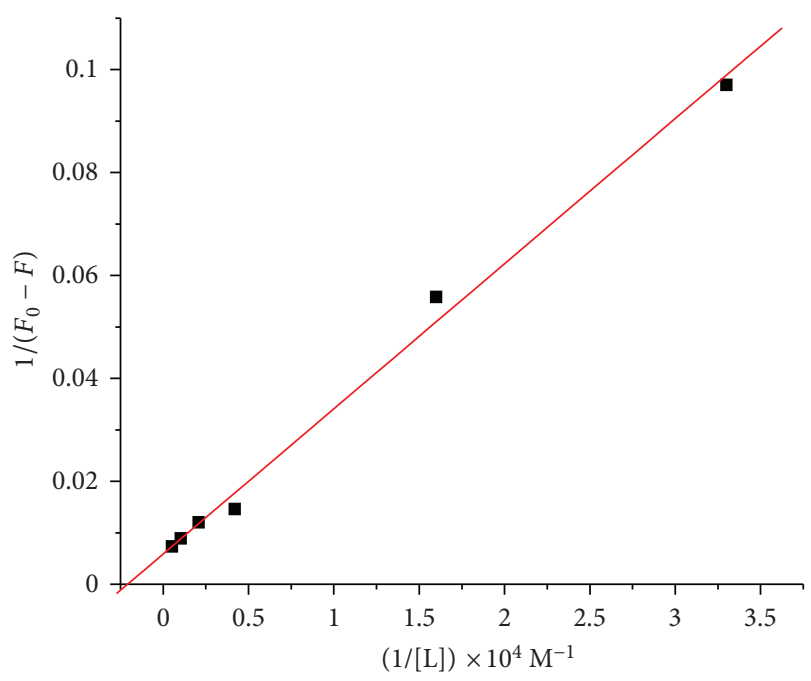

FIgURE 4: The plot of $1 /\left(F_{0}-F\right)$ versus $(1 /[L])$ for pentobarbital-TTR complexes.

characterized by AFM equipped with $4 \times 4 \mu \mathrm{m}^{2}$ piezoelectric scanner. Analysis were carried out using tapping mode at room temperature using AFM cantilevers with a spring constant $2 \mathrm{~N} / \mathrm{m}$ (Micro cantilever, OLYMPUS). All scanned images were analyzed using WSxM 5.0 Develop 3.2 software.

\section{Results}

The intrinsic fluorescence of many proteins is mainly contributed by tryptophan alone, because phenylalanine has very low quantum yield and the fluorescence of tyrosine is almost totally quenched if it is ionized or near an amino group, a carboxyl group, or a tryptophan residue [35]. The fluorescence spectra of TTR at various concentrations of pentobarbital $(0.03,0.06,0.24,0.48,0.96$, and 1.92) $\times 10^{-3} \mathrm{moLL}^{-1}$ are shown in Figure 2. The fluorescence intensity of TTR decreased regularly with the increase of pentobarbital concentration, while the peak position shows little or no change at all.

The dynamic quenching process can be described by the Stern-Volmer equation [37]:

$$
\frac{F_{0}}{F}=1+K_{q} \tau_{0}(L)=1+K_{\mathrm{sv}}(L),
$$

where $F$ and $F_{0}$ are the fluorescence intensity with and without quencher, $K_{q}$ is the quenching rate constant of the biomolecule, $K_{\mathrm{sv}}$ is the Stern-Volmer quenching constant, $\tau_{0}$ is the average lifetime of the biomolecule without quencher, and $(L)$ is the concentration of pentobarbital. As can be seen from Figure 3, the Stern-Volmer plot is linear and the slope is equal to $K_{\mathrm{sv}}\left(5.66 \times 10^{2} \mathrm{~L} \mathrm{moL}^{-1}\right)$. Fluorescence quenching can be induced by different mechanisms, which were usually classified into dynamic quenching and static quenching. Dynamic quenching arises from collisional encounters between the fluorophore and quencher and static quenching results from the formation of a ground state complex between the fluorophore and the quencher [38]. The quenching rate 


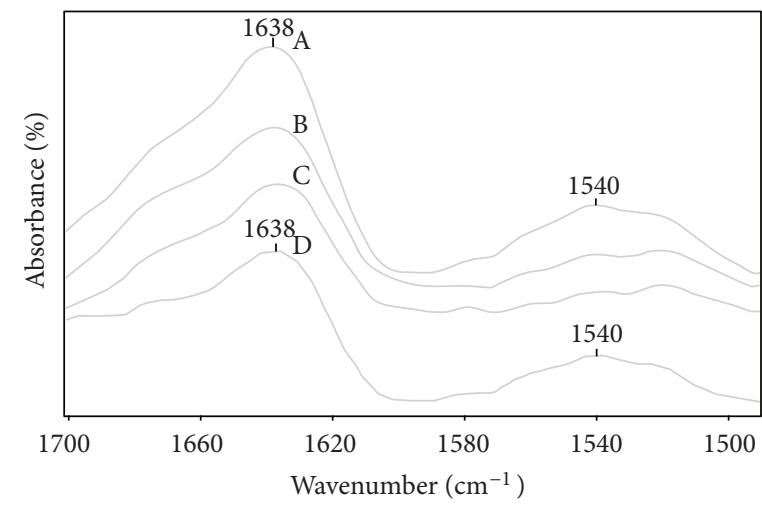

(A) TTR free $0.03 \mathrm{mg} / \mathrm{mL}$ (B) TTR + pento. $0.12 \mathrm{mM}$

(D) TTR + pento. $0.96 \mathrm{mM}$

(a)

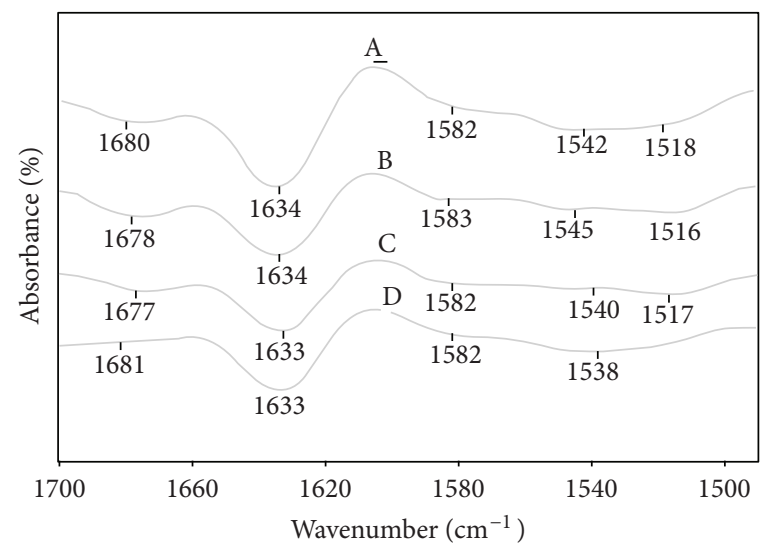

(A) TTR free $0.03 \mathrm{mg} / \mathrm{mL}$

(B) TTR + pento. $0.12 \mathrm{mM}$

(C) TTR + pento. $0.48 \mathrm{mM}$

(D) TTR + pento. $0.96 \mathrm{mM}$

FIGURE 5: (a) Absorbance spectra of TTR-pentobarbital complexes. (b) Second derivative of TTR-pentobarbital complexes spectra. (A, B, C, and $\mathrm{D})$ correspond to pentobarbital concentrations of $(0.0,0.12,0.48$, and $0.96 \mathrm{mM})$, respectively.

constant $K_{q}$, is calculated using the fluorescence life time of $10 \mathrm{~ns}$ [39] at $\left(K_{q}=5.66 \times 10^{10} \mathrm{~L} \mathrm{moL}^{-1} \mathrm{~s}^{-1}\right)$. This value is larger than the maximum dynamic quenching constant for various quenchers with biopolymer $\left(2 \times 10^{10} \mathrm{~L} \mathrm{moL}^{-1} \mathrm{~s}^{-1}\right)$ [40], which confirms that a static quenching is dominant in the formed complexes [41].

When the static quenching equation is used [38]

$$
\frac{1}{F_{0}-F}=\frac{1}{F_{0} K(L)}+\frac{1}{F_{0}},
$$

where $K$ is the binding constant of pentobarbital with TTR. The value of $K$ has been determined from the slope and the intercept in Figure 4 and is calculated at $2.092 \times 10^{3} \mathrm{M}^{-1}$ which supports the effective role of static quenching.

The FTIR absorption spectra in the amide I and amide II regions are taken for different concentrations of TTRpentobarbital samples. The analysis of the secondary structure of TTR in the amide I which occurs between $1600 \mathrm{~cm}^{-1}$ and $1700 \mathrm{~cm}^{-1}$ yields several components. The peaks of these components correspond to the $\mathrm{C}=\mathrm{O}$ stretching vibrations of the amide group, coupled to the $\mathrm{C}-\mathrm{N}$ stretching and $\mathrm{C}-\mathrm{C}-\mathrm{N}$ deformation mode [32]. The peaks in the amide II (1600-1480) $\mathrm{cm}^{-1}$ region are due to the coupling of the $\mathrm{N}-\mathrm{H}$ in-plane bending and $\mathrm{C}-\mathrm{N}$ stretching modes [42].

The component bands of the amide I and amide II regions were determined using FSD and second derivative resolution with curve fitting procedures. This procedure has provided a basis for the quantitative estimation of protein secondary structure [32-34, 43].

In this work a quantitative analysis of the protein secondary structure for TTR and pentobarbital-TTR complex in dehydrated films is determined from the shape of amide I and amide II bands. Figure 5 shows the spectra and its second derivative for the amide I and the amide II regions. The second derivative resolution enhancement and the curve-fitted graphs for the amide I and amide II regions are shown in Figure 6. The curve fitted graphs show the secondary structure determinations of the TTR free and pentobarbital-TTR complexes. The exact frequency of the vibrations depend on the nature of the hydrogen bonding involving the amide group, and by the particular secondary structure adopted by the protein. In Table 1 we have listed the peak positions of the separate components of the amide I and amide II regions using both second derivative and FSD procedures.

The quantitative estimation of protein secondary structure is based on the assumption that the total absorption due to $\mathrm{C}=\mathrm{O}$ vibration can be represented by the sum of the individual absorptions due to the vibrations of the separate elements of the band [33].

The percentages of each secondary structure of the pentobarbital TTR complexes were calculated from the integrated areas of the component bands in amide I and amide II respectively. Table 2 shows the relative intensity of each secondary structure component of TTR before and after the interaction with pentobarbital at different concentrations. The percentage values of the relative intensities of the components of amide I for free TTR are in agreement with the results of other recent spectroscopic studies [32,34]. The peaks of the amide II showed similar proportionalities in their percentage values to that of amide I.

The relative intensity of the $\beta$-sheet band with its peak at $\left(1631 \mathrm{~cm}^{-1}\right)$ shows a remarkable decrease with the increase in pentobarbital concentrations, shown in Figure 7(a). A similar observation can be made for the $\beta$-sheet band at $\left(1499 \mathrm{~cm}^{-1}\right)$ in the amide II region as shown in Figure 7(b). On the other hand an increase in the relative intensities of the bands at $\left(1694 \mathrm{~cm}^{-1}, 1611 \mathrm{~cm}^{-1}, 1582 \mathrm{~cm}^{-1}\right.$, and $\left.1507 \mathrm{~cm}^{-1}\right)$ are noted with the increase of pentobarbital concentrations 


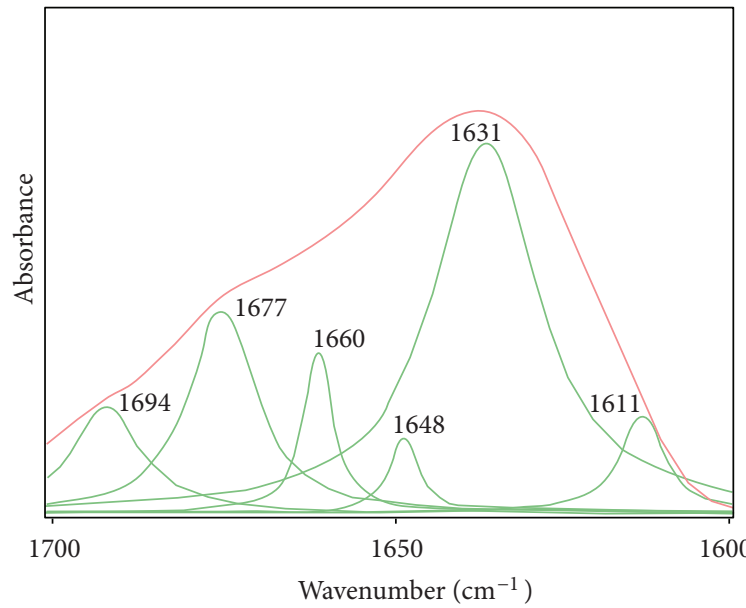

(a)

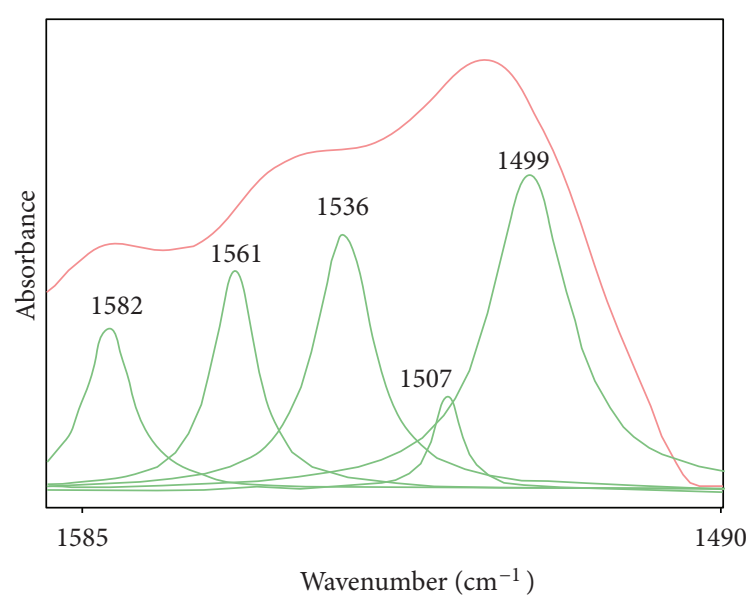

(c)

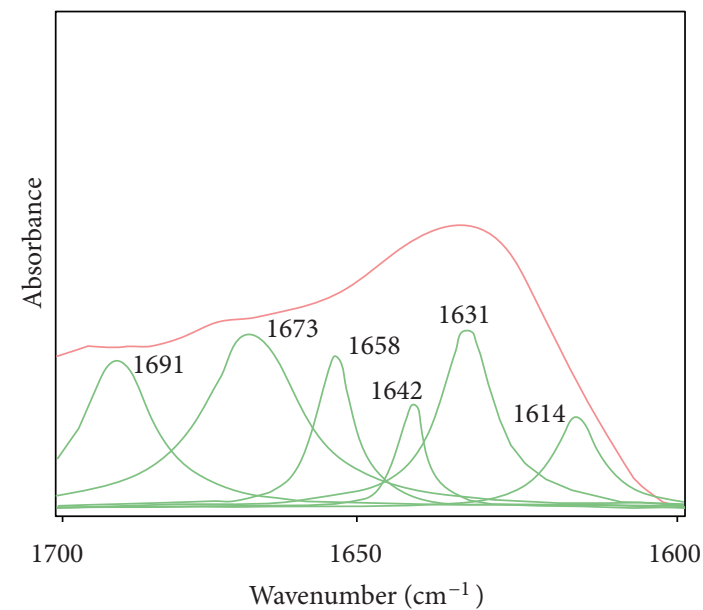

(b)

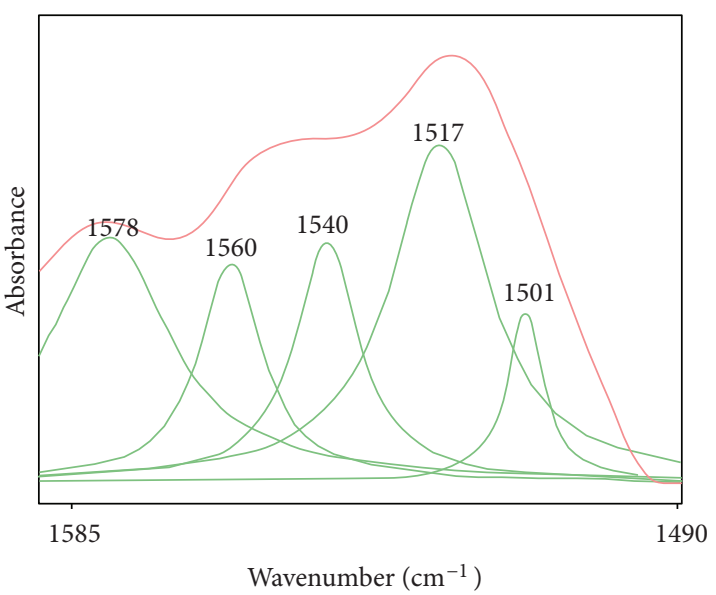

(d)

FIGURE 6: Curve-fitted graphs for (a) free TTR in amide I region, (b) TTR-pentobarbital complex with 0.96 mM pentobarbital concentrations in amide I region, (c) free TTR in amide II region, and (d) TTR-pentobarbital complexes with $0.96 \mathrm{mM}$ pentobarbital concentration in amide II region.

TABLE 1: Band assignment in the absorption spectra of TTR with different pentobarbital concentrations for amide I and amide II regions.

\begin{tabular}{|c|c|c|c|c|}
\hline Bands & TTR free & TTR + pento. $0.12 \mathrm{mM}$ & TTR + pento. $0.48 \mathrm{mM}$ & TTR + pento. $0.96 \mathrm{mM}$ \\
\hline \multirow{6}{*}{$\begin{array}{l}\text { Amide I } \\
1600-1700 \mathrm{~cm}^{-1}\end{array}$} & 1611 & 1614 & 1615 & 1614 \\
\hline & 1631 & 1631 & 1631 & 1632 \\
\hline & 1648 & 1644 & 1645 & 1642 \\
\hline & 1660 & 1658 & 1658 & 1658 \\
\hline & 1677 & 1674 & 1674 & 1673 \\
\hline & 1694 & 1692 & 1692 & 1691 \\
\hline \multirow{5}{*}{$\begin{array}{l}\text { Amide II } \\
1490-1590 \mathrm{~cm}^{-1}\end{array}$} & 1499 & 1499 & 1501 & 1501 \\
\hline & 1507 & 1519 & 1517 & 1517 \\
\hline & 1536 & 1538 & 1540 & 1540 \\
\hline & 1561 & 1561 & 1560 & 1560 \\
\hline & 1582 & 1581 & 1579 & 1578 \\
\hline
\end{tabular}




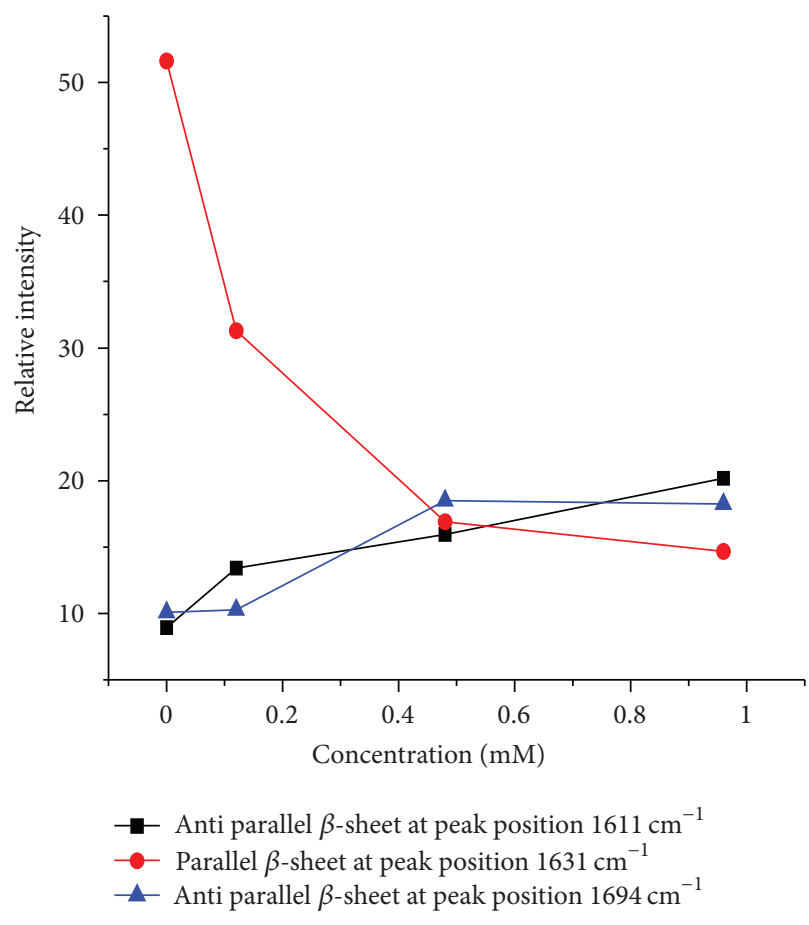

(a)

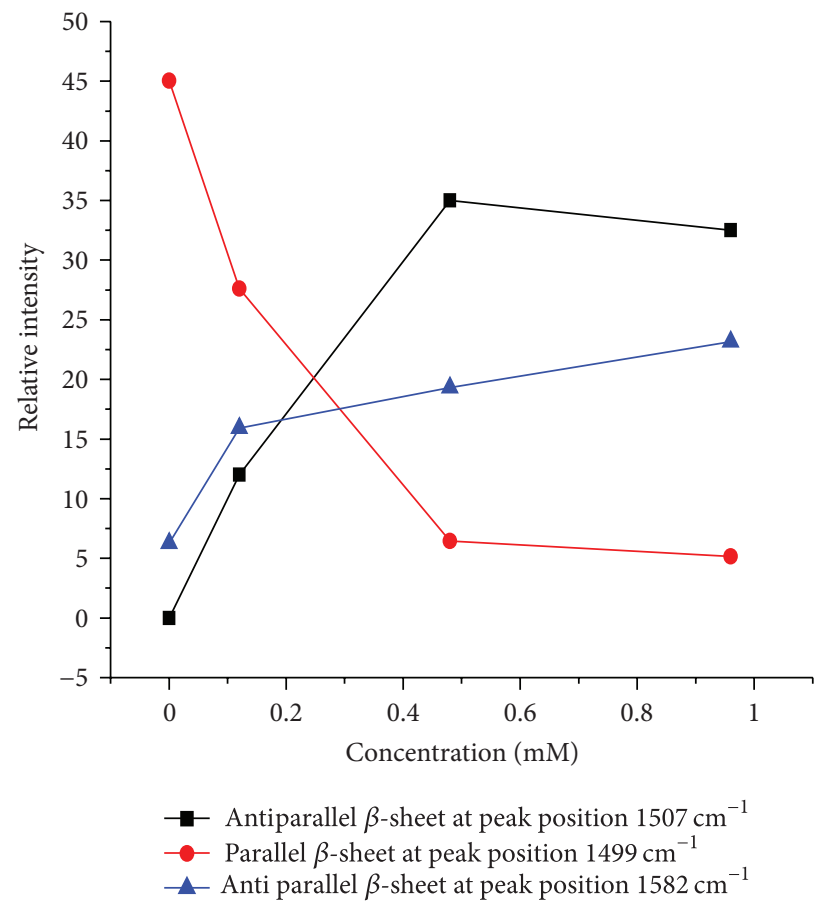

(b)

FIGURE 7: Relative intensity variation for different concentrations of TTR-pentobarbital complexes in (a) amide I region and (b) amide II region.

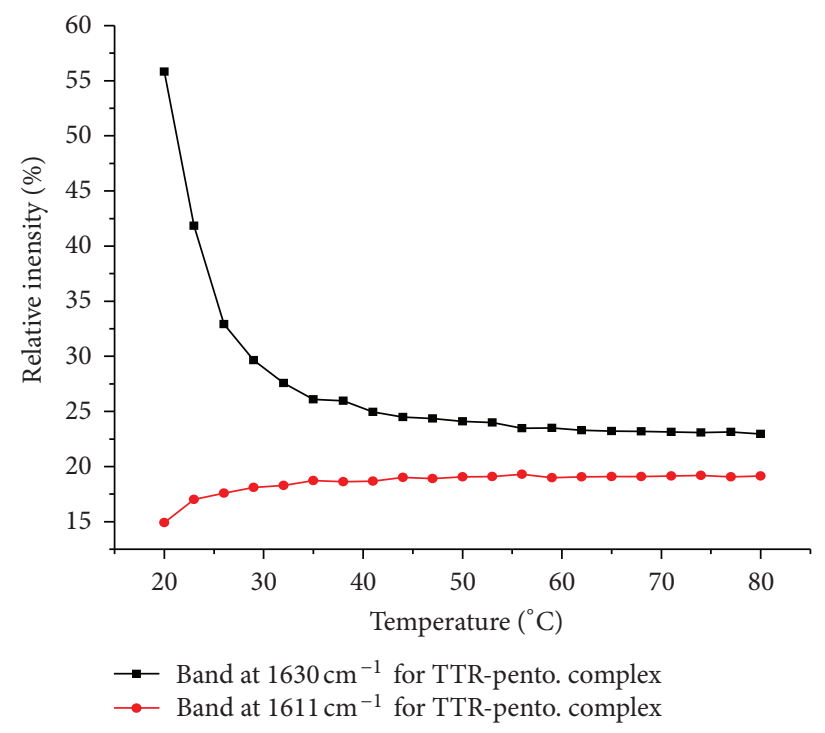

(a)

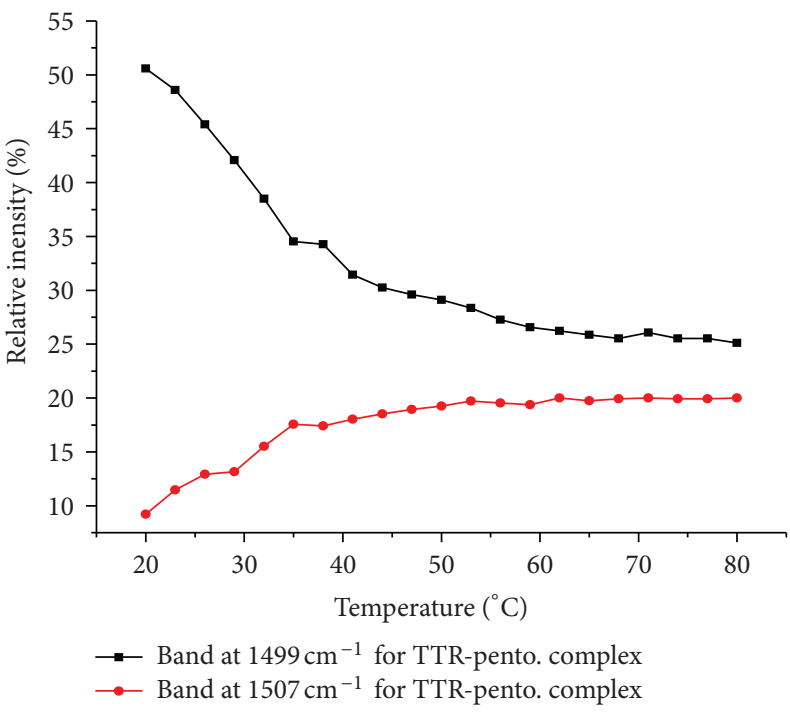

(b)

FIGURE 8: Relative intensity versus temperature change pentobarbital $1.92 \mathrm{mM}$ complexes (a) the bands at $1630 \mathrm{~cm}^{-1}$ and $1611 \mathrm{~cm}^{-1}$ (b) the band at $1507 \mathrm{~cm}^{-1}$ and $1499 \mathrm{~cm}^{-1}$.

in the protein complexes as shown in the same figures. The changes in the relative intensities can also be observed directly from the curve fitted graphs in Figure 6.

The variation of intensities with temperature change for the parallel and antiparallel $\beta$-sheets in TTR free and pentobarbital-TTR complexes are shown in Figure 8(a) for the amide II region and Figure 8(b) for the amide I region. The relative intensity increases as temperature increases for the antiparallel $\beta$-sheets while it remarkably decreases for the parallel $\beta$-sheets. The reduction of parallel $\beta$-sheets intensity percentage in favour of the increase of the antiparallel $\beta$-sheets structures are believed to be due to the unfolding 
TABLE 2: Percentages of secondary structure components in the amide I and amide II regions of TTR and its pentobarbital complexes.

\begin{tabular}{|c|c|c|c|c|}
\hline Bands & TTR free & $\mathrm{TTR}+$ pento $0.12 \mathrm{mM}$ & TTR + pento $0.48 \mathrm{mM}$ & $\mathrm{TTR}+$ pento $0.96 \mathrm{mM}$ \\
\hline \multicolumn{5}{|l|}{ Amide I } \\
\hline $\begin{array}{l}\text { Parallel } \beta \text {-sheet } \\
\left(1621-1640 \mathrm{~cm}^{-1}\right)\end{array}$ & 51.6 & 31.3 & 16.9 & 14.7 \\
\hline $\begin{array}{l}\text { Random Coil } \\
\left(1640-1652 \mathrm{~cm}^{-1}\right)\end{array}$ & 1.7 & 3.4 & 4.2 & 4.0 \\
\hline $\begin{array}{l}\alpha \text {-helix } \\
\left(1652-1666 \mathrm{~cm}^{-1}\right)\end{array}$ & 6.3 & 8.3 & 7.8 & 8.9 \\
\hline $\begin{array}{l}\beta \text {-turns } \\
\left(1666-1685 \mathrm{~cm}^{-1}\right)\end{array}$ & 21.3 & 33.4 & 36.6 & 33.9 \\
\hline $\begin{array}{l}\text { Antiparallel } \beta \text {-sheets } \\
\left(1600-1621 \mathrm{~cm}^{-1}\right) \\
\left(1685-1700 \mathrm{~cm}^{-1}\right)\end{array}$ & $\begin{array}{c}8.9 \\
10.1\end{array}$ & $\begin{array}{l}13.4 \\
10.3\end{array}$ & $\begin{array}{l}16.0 \\
18.5\end{array}$ & $\begin{array}{l}20.2 \\
18.3\end{array}$ \\
\hline \multicolumn{5}{|l|}{ Amide II } \\
\hline $\begin{array}{l}\text { Parallel } \beta \text {-sheet } \\
\left(1490-1507 \mathrm{~cm}^{-1}\right)\end{array}$ & 45.0 & 27.6 & 6.4 & 5.2 \\
\hline $\begin{array}{l}\text { Antiparallel } \beta \text {-sheet } \\
\left(1507-1528 \mathrm{~cm}^{-1}\right)\end{array}$ & 0.14 & 12.1 & 35.2 & 32.6 \\
\hline $\begin{array}{l}\alpha \text {-helix } \\
\left(1528-1550 \mathrm{~cm}^{-1}\right)\end{array}$ & 23.2 & 18.9 & 17.4 & 18.9 \\
\hline $\begin{array}{l}\beta \text {-turns } \\
\left(1550-1570 \mathrm{~cm}^{-1}\right)\end{array}$ & 25.3 & 25.5 & 21.6 & 20.17 \\
\hline $\begin{array}{l}\text { Antiparallel } \beta \text {-sheets } \\
\left(1570-1590 \mathrm{~cm}^{-1}\right)\end{array}$ & 6.3 & 15.9 & 19.3 & 23.2 \\
\hline
\end{tabular}

of the protein in the presence of pentobarbital as a result of the formation of H-bonding between TTR and pentobarbital [44].

AFM techniques are used as additional method to investigate the effect of pentobarbital on TTR by taking images for TTR solution and then for TTR-pentobarbital complex as shown in Figure 9. These figures confirm the formation of oligomers seen as spherical shaped objects $(30-50 \mathrm{~nm}$ in diameter) which support previously established characterization of oligomers $[36,43,45]$.

\section{Discussion}

The difference in behavior for the two types of $\beta$-sheets is mainly due to the different amino acids and their preferred secondary structural arrangements. It has been reported that the two forms of $\beta$-sheets have different thermodynamic propensity scales [46]. The gradual decrease in intensity for the bands of parallel $\beta$-sheets $\left(1631 \mathrm{~cm}^{-1}\right.$ and $\left.1499 \mathrm{~cm}^{-1}\right)$ with increasing temperatures are believed to be mainly due to the unfolding of the protein as a result of the formation of H-bonding between TTR and pentobarbital. The newly formed $\mathrm{H}$-bonding causes the $\mathrm{C}-\mathrm{N}$ bond to assume a partial double bond character due to electrons flow from the $\mathrm{C}=\mathrm{O}$ to the $\mathrm{C}-\mathrm{N}$ bond which decreases the intensity of the molecular vibrations [47]. On the other hand the increase of intensity for antiparallel $\beta$ sheets as shown in Figure 8 implies more stability and less conversions of the $\mathrm{C}=\mathrm{O}$ bond as a result of the interaction with pentobarbital. The parallel arrangement is less stable because the geometry of the individual amino acid molecules forces the hydrogen bonds to occur at an angle, making them longer and thus weaker. Contrarily, in the antiparallel arrangement the hydrogen bonds are aligned directly opposite to each other and it allows the interstrand hydrogen bonds between carbonyls and amines to be planar making stronger and more stable bonds [48].

According to Giorgia Zandomeneghi there is structural difference between $\beta$-sheets in native proteins and amyloid fibrils [34]. In their work, parallel $\beta$-sheet reported at $1630 \mathrm{~cm}^{-1}$ while amyloid fibrils are reported at $1615 \mathrm{~cm}^{-1}$. The analysis of the absorption spectra of pentobarbital-TTR complex has shown a decrease in the intensity of the parallel $\beta$-sheet band at $1631 \mathrm{~cm}^{-1}$ accompanied by a simultaneous increase in the intensities of the bands at $1611 \mathrm{~cm}^{-1}$ and $1694 \mathrm{~cm}^{-1}$ Figure 6, which is typical for antiparallel $\beta$ sheet formation. This noticeable increase in intensity of the $1611 \mathrm{~cm}^{-1}$ peak can be related to the formation of fibrils or oligmers as a result of the TTR interaction with pentobarbital. A similar effect has been observed in the amide II region where an increase in the relative intensity of the peak at $1507 \mathrm{~cm}^{-1}$ is accompanied with a decrease in the relative intensity of the peak at $1499 \mathrm{~cm}^{-1}$. The increase of pentobarbital concentration in the protein complex has shown a larger increase in the relative intensities of the peaks at $1611 \mathrm{~cm}^{-1}, 1694 \mathrm{~cm}^{-1}$, and $1507 \mathrm{~cm}^{-1}$ while the intensities of the two peaks at 1630 and $1499 \mathrm{~cm}^{-1}$ have decreased as shown in Figure 7.

The slight shifts in the peak positions of $\left(1611 \mathrm{~cm}^{-1}\right.$ and $1507 \mathrm{~cm}^{-1}$ ) are mainly due to the interaction of pentobarbital 


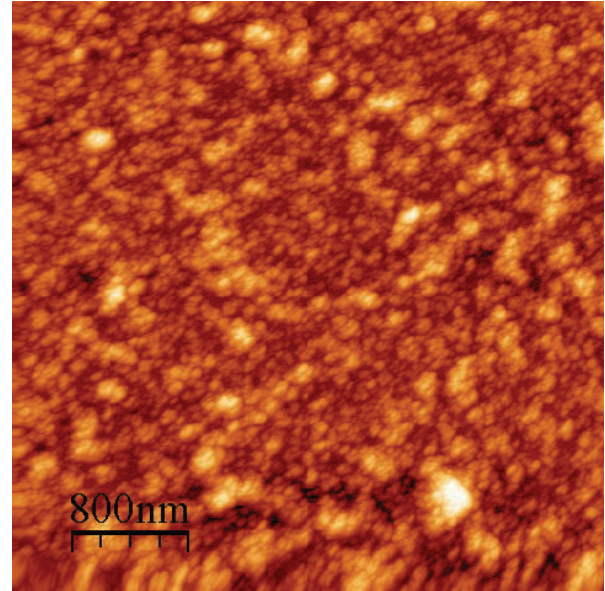

(a)

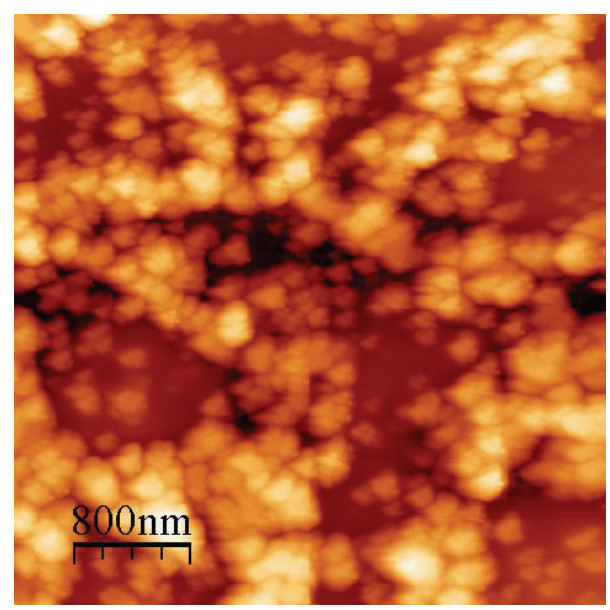

(b)

FIgURE 9: AFM Images of (a) TTR free and (b) TTR + Pentobarbital $7.68 \mathrm{mM}$ concentration.

with TTR turning more $\beta$-sheets into oligomer structure which causes permanent unfolding of the sheets producing insoluble structure [49]. The nature of this interaction can be explained in terms of the electrostatic interactions among surface charges on the protein $[50,51]$. The charge-charge interaction contributes to polarization of the structure in between these surfaces creating large stable structures in the form of oligomers as suggested by Ferández [52].

In our case we suggest that oligomer structure can be formed by assuming that pentobarbital molecules play the role of polarized dielectric material sandwiched between the unfolded $\beta$-sheets creating a capacitor-like structure, which raises the internal energy of the arrangement leading to a more stable complex. The developed rigid structure is expected to stop the $\beta$-sheets from folding due to the additional constrained on its surface leading to an insoluble oligomer. The size of the formed structure are determined by AFM measurements to be in the range of $(30-50 \mathrm{~nm}$ in diameter) which indicates to some extent that the structure is more likely in the form of oligomers as supported by other previous works [53-56]. Other studies have proposed that some ligands can work as a kinetic stabilizer by binding to the hormone binding sites in TTR which increase the freeenergy barrier for native tetramer dissociation [57]. All of these research results demonstrate the feasibility of using small molecules to stabilize the native fold of a potentially amyloidogenic human protein, thus preventing the conformational changes, which appear to be the common link in several human amyloid diseases [58].

In conclusion, the binding of pentobarbital to TTR has been investigated by fluorescence and FTIR spectroscopy. The value of the binding constant has been determined, the results indicate that the intrinsic fluorescence of TTR was quenched by pentobarbital through static quenching mechanism. We have demonstrated by using AFM and FTIR spectroscopy that pentobarbital interaction with TTR can trigger the conversion of $\beta$-sheets into insoluble oligimor structure. In addition we proposed that TTR amyloidogenesis can easily be the result of polymerization mechanism due to protein interaction with small anesthetics molecules leading to oligomerization. Current research indicates that oligomer formation leads to memory impairment causing Alzheimer and other brain diseases [59-61]. Further investigations are still needed to explain the role of anesthetics in initiating oligomer formation in proteins, and more clinical studies are needed to test these expectations.

\section{Acknowledgment}

This work is supported by the German Research Foundation DFG Grant no. DR228/24-2.

\section{References}

[1] C. C. F. Blake, M. J. Geisow, S. J. Oatley, B. Rerat, and C. Rerat, "Structure of prealbumin: secondary, tertiary and quaternary interactions determined by fourier refinement at $1.8 \AA$ A," Journal of Molecular Biology, vol. 121, no. 3, pp. 339-356, 1978.

[2] M. M. Sousa and M. J. Saraiva, "Neurodegeneration in familial amyloid polyneuropathy: from pathology to molecular signaling," Progress in Neurobiology, vol. 71, no. 5, pp. 385-400, 2003.

[3] C. C. F. Blake, I. D. A. Swan, C. Rerat, J. Berthou, A. Laurent, and B. Rerat, "An X-ray study of the subunit structure of prealbumin," Journal of Molecular Biology, vol. 61, no. 1, pp. 217-224, 1971.

[4] A. R. Aldred, C. M. Brack, and G. Schreiber, "The cerebral expression of plasma protein genes in differential species," Comparative Biochemistry and Physiology, vol. 111, no. 1, pp. 1-15, 1995.

[5] P. Felding and G. Fex, "Cellular origin of prealbumin in the rat," Biochimica et Biophysica Acta, vol. 716, no. 3, pp. 446-449, 1982.

[6] S. Mita, S. Maeda, K. Shimada, and S. Araki, "Analyses of prealbumin mRNAs in individuals with familial amyloidotic polyneuropathy," Journal of Biochemistry, vol. 100, no. 5, pp. 1215-1222, 1986.

[7] J. T. White and J. W. Kelly, "Support for the multigenic hypothesis of amyloidosis: the binding stoichiometry of retinolbinding protein, vitamin $\mathrm{A}$, and thyroid hormone influences transthyretin amyloidogenicity in vitro," Proceedings of the National Academy of Sciences of the United States of America, vol. 98, no. 23, pp. 13019-13024, 2001. 
[8] P. D. Larsen and L. DeLallo, "Cerebrospinal fluid transthyretin in the neonate and blood-cerebrospinal fluid barrier permeability," Annals of Neurology, vol. 25, no. 6, pp. 628-630, 1989.

[9] C. M. H. Watanabe, S. Wolffram, P. Ader et al., "The in vivo neuromodulatory effects of the herbal medicine Ginkgo biloba," Proceedings of the National Academy of Sciences of the United States of America, vol. 98, no. 12, pp. 6577-6580, 2001.

[10] T. D. Stein, N. J. Anders, C. DeCarli, S. L. Chan, M. P. Mattson, and J. A. Johnson, "Neutralization of transthyretin reverses the neuroprotective effects of secreted amyloid precursor protein (APP) in APPSw mice resulting in tau phosphorylation and loss of hippocampal neurons: support for the amyloid hypothesis," Journal of Neuroscience, vol. 24, no. 35, pp. 7707-7717, 2004.

[11] T. D. Stein and J. A. Johnson, "Lack of neurodegeneration in transgenic mice overexpressing mutant amyloid precursor protein is associated with increased levels of transthyretin and the activation of cell survival pathways," Journal of Neuroscience, vol. 22, no. 17, pp. 7380-7388, 2002.

[12] P. Hammarström, R. L. Wiseman, E. T. Powers, and J. W. Kelly, "Prevention of transthyretin arnyloid disease by changing protein misfolding energetics," Science, vol. 299, no. 5607, pp. 713-716, 2003.

[13] F. Schneider, P. Hammarström, and J. W. Kelly, “Transthyretin slowly exchanges subunits under physiological conditions: a convenient chromatographic method to study subunit exchange in oligomeric proteins," Protein Science, vol. 10, no. 8, pp. 1606-1613, 2001.

[14] X. Jiang, J. N. Buxbaum, and J. W. Kelly, "The V122I cardiomyopathy variant of transthyretin increases the velocity of rate-limiting tetramer dissociation, resulting in accelerated amyloidosis," Proceedings of the National Academy of Sciences of the United States of America, vol. 98, no. 26, pp. 14943-14948, 2001.

[15] C. M. Dobson, "Protein folding and misfolding," Nature, vol. 426, no. 6968, pp. 884-890, 2003.

[16] M. Stefani and C. M. Dobson, "Protein aggregation and aggregate toxicity: new insights into protein folding, misfolding diseases and biological evolution," Journal of Molecular Medicine, vol. 81, no. 11, pp. 678-699, 2003.

[17] V. N. Uversky and A. L. Fink, "Conformational constraints for amyloid fibrillation: the importance of being unfolded," Biochimica et Biophysica Acta, vol. 1698, no. 2, pp. 131-153, 2004.

[18] D. M. Walsh and D. J. Selkoe, "Oligomers in the brain: the emerging role of soluble protein aggregates in neurodegeneration," Protein and Peptide Letters, vol. 11, no. 3, pp. 213-228, 2004.

[19] M. M. Sousa and M. J. Saraiva, "Neurodegeneration in familial amyloid polyneuropathy: from pathology to molecular signaling," Progress in Neurobiology, vol. 71, no. 5, pp. 385-400, 2003.

[20] D. M. Walsh and D. J. Selkoe, "A $\beta$ oligomers-a decade of discovery," Journal of Neurochemistry, vol. 101, no. 5, pp. 1172-1184, 2007.

[21] H. A. Lashuel, D. Hartley, B. M. Petre, T. Walz, and P. T. Lansbury Jr., "Neurodegenerative disease: amyloid pores from pathogenic mutations," Nature, vol. 418, p. 291, 2002.

[22] P. K. Mandal and J. W. Pettegrew, "Alzheimer's disease: soluble oligomeric $\mathrm{A} \beta(1-40)$ peptide in membrane mimic environment from solution NMR and circular dichroism studies," Neurochemical Research, vol. 29, no. 12, pp. 2267-2272, 2004.
[23] P. Hammarström, F. Schneider, and J. W. Kelly, "Transsuppression of misfolding in an amyloid disease," Science, vol. 293, no. 5539, pp. 2459-2462, 2001.

[24] A. Quintas, D. C. Vaz, I. Cardoso, M. J. M. Saraiva, and R. M. M. Brito, "Tetramer dissociation and monomer partial unfolding precedes protofibril formation in amyloidogenic transthyretin variants," Journal of Biological Chemistry, vol. 276, no. 29, pp. 27207-27213, 2001.

[25] N. I. L. J. Bohnen, M. A. Warner, E. Kokmen, C. M. Beard, and L. T. Kurland, "Alzheimer's disease and cumulative exposure to anesthesia: a case-control study," Journal of the American Geriatrics Society, vol. 42, no. 2, pp. 198-201, 1994.

[26] S. Muravchick and D. S. Smith, "Parkinsonian symptoms during emergence from general anesthesia," Anesthesiology, vol. 82, no. 1, pp. 305-307, 1995.

[27] A. Carnini, J. D. Lear, and R. G. Eckenhoff, "Inhaled anesthetic modulation of amyloid $\beta 1-40$ assembly and growth," Current Alzheimer Research, vol. 4, no. 3, pp. 233-241, 2007.

[28] Z. Xie, Y. Dong, U. Maeda et al., "The common inhalation anesthetic isoflurane induces apoptosis and increases amyloid $\beta$ protein levels," Anesthesiology, vol. 104, no. 5, pp. 988-994, 2006.

[29] S. A. Peterson, T. Klabunde, H. A. Lashuel, H. Purkey, J. C. Sacchettini, and J. W. Kelly, "Inhibiting transthyretin conformational changes that lead to amyloid fibril formation," Proceedings of the National Academy of Sciences of the United States of America, vol. 95, no. 22, pp. 12956-12960, 1998.

[30] F. Chiti and C. M. Dobson, "Amyloid formation by globular proteins under native conditions," Nature Chemical Biology, vol. 5, no. 1, pp. 15-22, 2009.

[31] H. Susi and D. M. Byler, "Resolution-enhanced fourier transform infrared spectroscopy of enzymes," Methods in Enzymology, vol. 130, pp. 290-311, 1986.

[32] Y. Cordeiro, J. Kraineva, M. C. Suarez et al., "Fourier transform infrared spectroscopy provides a fingerprint for the tetramer and for the aggregates of transthyretin," Biophysical Journal, vol. 91, no. 3, pp. 957-967, 2006.

[33] J. Kong and S. Yu, "Fourier transform infrared spectroscopic analysis of protein secondary structures," Acta Biochimica et Biophysica Sinica, vol. 39, no. 8, pp. 549-559, 2007.

[34] G. Zandomeneghi, M. R. H. Krebs, M. G. McCammon, and M. Fändrich, "FTIR reveals structural differences between native $\beta$-sheet proteins and amyloid fibrils," Protein Science, vol. 13, no. 12, pp. 3314-3321, 2004.

[35] R. Sarroukh, E. Cerf, S. Derclaye et al., "Transformation of amyloid $\beta(1-40)$ oligomers into fibrils is characterized by a major change in secondary structure," Cellular and Molecular Life Sciences, vol. 68, no. 8, pp. 1429-1438, 2011.

[36] E. Cerf, R. Sarroukh, S. Tamamizu-Kato et al., "Antiparallel $\beta$-sheet: a signature structure of the oligomeric amyloid $\beta$ peptide," Biochemical Journal, vol. 421, no. 3, pp. 415-423, 2009.

[37] J. N. Tian, J. Q. Liu, J. Y. Zhang, Z. D. Hu, and X. Chen, "Fluorescence studies on the interactions of barbaloin with bovine serum albumin," Chemical and Pharmaceutical Bulletin, vol. 51, no. 5, pp. 579-582, 2003.

[38] J. R. Lakowicz, Principles of Fluorescence Spectroscopy, Kluwer Academic Publishers/Plenum, New York, NY, USA, 1999.

[39] G. Z. Chen, X. Z. Huang, J. G. Xu, Z. Z. Zheng, and Z. B. Wang, Methods of Florescence Analysis, Science Press, Beijing, China, 2nd edition, 1990. 
[40] J. R. Lakowicz and G. Weber, "Quenching of fluorescence by oxygen. A probe for structural fluctuations in macromolecules," Biochemistry, vol. 12, no. 21, pp. 4161-4170, 1973.

[41] T. Wang, B. Xiang, Y. Wang et al., "Spectroscopic investigation on the binding of bioactive pyridazinone derivative to human serum albumin and molecular modeling," Colloids and Surfaces $B$, vol. 65, no. 1, pp. 113-119, 2008.

[42] V. A. Sirotkin, A. N. Zinatullin, B. N. Solomonov, D. A. Faizullin, and V. D. Fedotov, "Calorimetric and Fourier transform infrared spectroscopic study of solid proteins immersed in low water organic solvents," Biochimica et Biophysica Acta, vol. 1547, no. 2, pp. 359-369, 2001.

[43] D. M. Byler, J. N. Brouilette, and H. Susi, "Quantitative studies of protein structure by FT-IR spectral deconvolution and curve fitting," Spectroscopy, vol. 1, no. 3, pp. 29-32, 1986.

[44] S. M. Darwish, S. E. Abu sharkh, M. M. Abu Teir, S. A. Makharza, and M. M. Abu-hadid, "Spectroscopic investigations of pentobarbital interaction with human serum albumin," Journal of Molecular Structure, vol. 963, no. 2-3, pp. 122-129, 2010.

[45] M. Lindgren, K. Sörgjerd, and P. Hammarström, "Detection and characterization of aggregates, prefibrillar amyloidogenic oligomers, and protofibrils using fluorescence spectroscopy," Biophysical Journal, vol. 88, no. 6, pp. 4200-4212, 2005.

[46] C. A. Kim and J. M. Berg, “Thermodynamic $\beta$-sheet propensities measured using a zinc-finger host peptide," Nature, vol. 362, no. 6417 , pp. 267-270, 1993.

[47] H. Fabian, C. Schultz, D. Naumann, O. Landt, U. Hahn, and W. Saenger, "Secondary structure and temperature-induced unfolding and refolding of ribonuclease T1 in aqueous solution. A Fourier transform infrared spectroscopic study," Journal of Molecular Biology, vol. 232, no. 3, pp. 967-981, 1993.

[48] A. Perczel, Z. Gáspári, and I. G. Csizmadia, "Structure and stability of $\beta$-pleated sheets," Journal of Computational Chemistry, vol. 26, no. 11, pp. 1155-1168, 2005.

[49] V. L. Shnyrov, E. Villar, G. G. Zhadan et al., "Comparative calorimetric study of non-amyloidogenic and amyloidogenic variants of the homotetrameric protein transthyretin," Biophysical Chemistry, vol. 88, no. 1-3, pp. 61-67, 2000.

[50] C. N. Pace, "Single surface stabilizer," Nature Structural Biology, vol. 7, no. 5, pp. 345-346, 2000.

[51] X. Hou, A. Mechler, L. L. Martin, M. I. Aguilar, and D. H. Small, "Cholesterol and anionic phospholipids increase the binding of amyloidogenic transthyretin to lipid membranes," Biochimica et Biophysica Acta, vol. 1778, no. 1, pp. 198-205, 2008.

[52] A. Fernández, "What factor drives the fibrillogenic association of $\beta$-sheets?” FEBS Letters, vol. 579, no. 29, pp. 6635-6640, 2005.

[53] X. Hou, H. C. Parkington, H. A. Coleman et al., "Transthyretin oligomers induce calcium influx via voltage-gated calcium channels," Journal of Neurochemistry, vol. 100, no. 2, pp. 446-457, 2007.

[54] M. Lindgren and P. Hammarström, "Amyloid oligomers: spectroscopic characterization of amyloidogenic protein states," FEBS Journal, vol. 277, no. 6, pp. 1380-1388, 2010.

[55] R. G. Eckenhoff, J. S. Johansson, H. Wei et al., "Inhaled anesthetic enhancement of amyloid- $\beta$ oligomerization and cytotoxicity," Anesthesiology, vol. 101, no. 3, pp. 703-709, 2004.

[56] P. Hammarström, X. Jiang, A. R. Hurshman, E. T. Powers, and J. W. Kelly, "Sequence-dependent denaturation energetics: a major determinant in amyloid disease diversity," Proceedings of the National Academy of Sciences of the United States of America, vol. 99, no. 4, pp. 16427-16432, 2002.
[57] J. M. Sanchez-Ruiz, "Protein kinetic stability," Biophysical Chemistry, vol. 148, no. 1-3, pp. 1-15, 2010.

[58] G. J. Miroy, Z. Lai, H. A. Lashuel, S. A. Peterson, C. Strang, and J. W. Kelly, "Inhibiting transthyretin amyloid fibril formation via protein stabilization," Proceedings of the National Academy of Sciences of the United States of America, vol. 93, no. 26, pp. 15051-15056, 1996.

[59] M. Renner, P. N. Lacor, P. T. Velasco et al., "Deleterious effects of amyloid $\beta$ oligomers acting as an extracellular scaffold for mGluR5," Neuron, vol. 66, no. 5, pp. 739-754, 2010.

[60] K. Broersen, F. Rousseau, and J. Schymkowitz, "The culprit behind amyloid beta peptide related neurotoxicity in Alzheimer's disease: oligomer size or conformation?" Alzheimer's Research \& Therapy, vol. 2, no. 4, article 12, 2010.

[61] X. Bi, "Alzheimer disease: update on basic mechanisms," The Journal of the American Osteopathic Association, vol. 110, no. 9, article 8, pp. 53-59, 2010. 

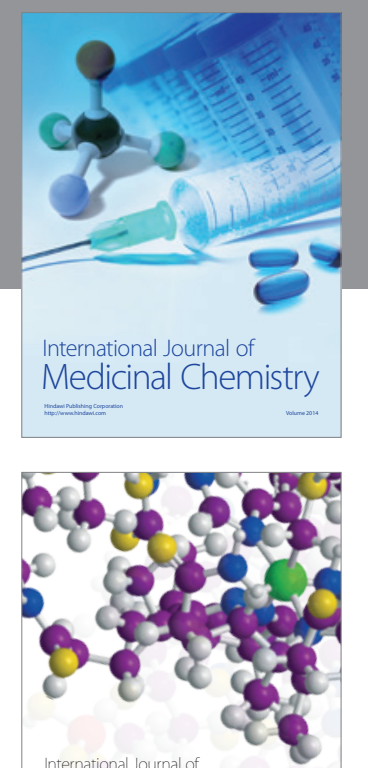

\section{Carbohydrate} Chemistry

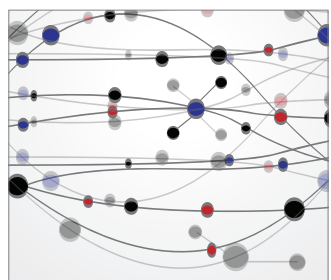

The Scientific World Journal
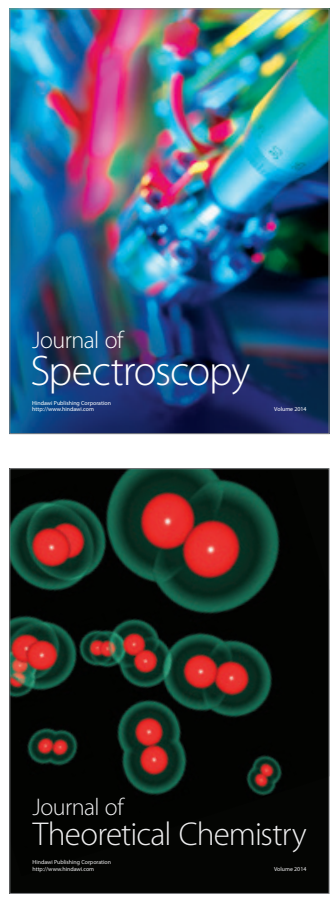
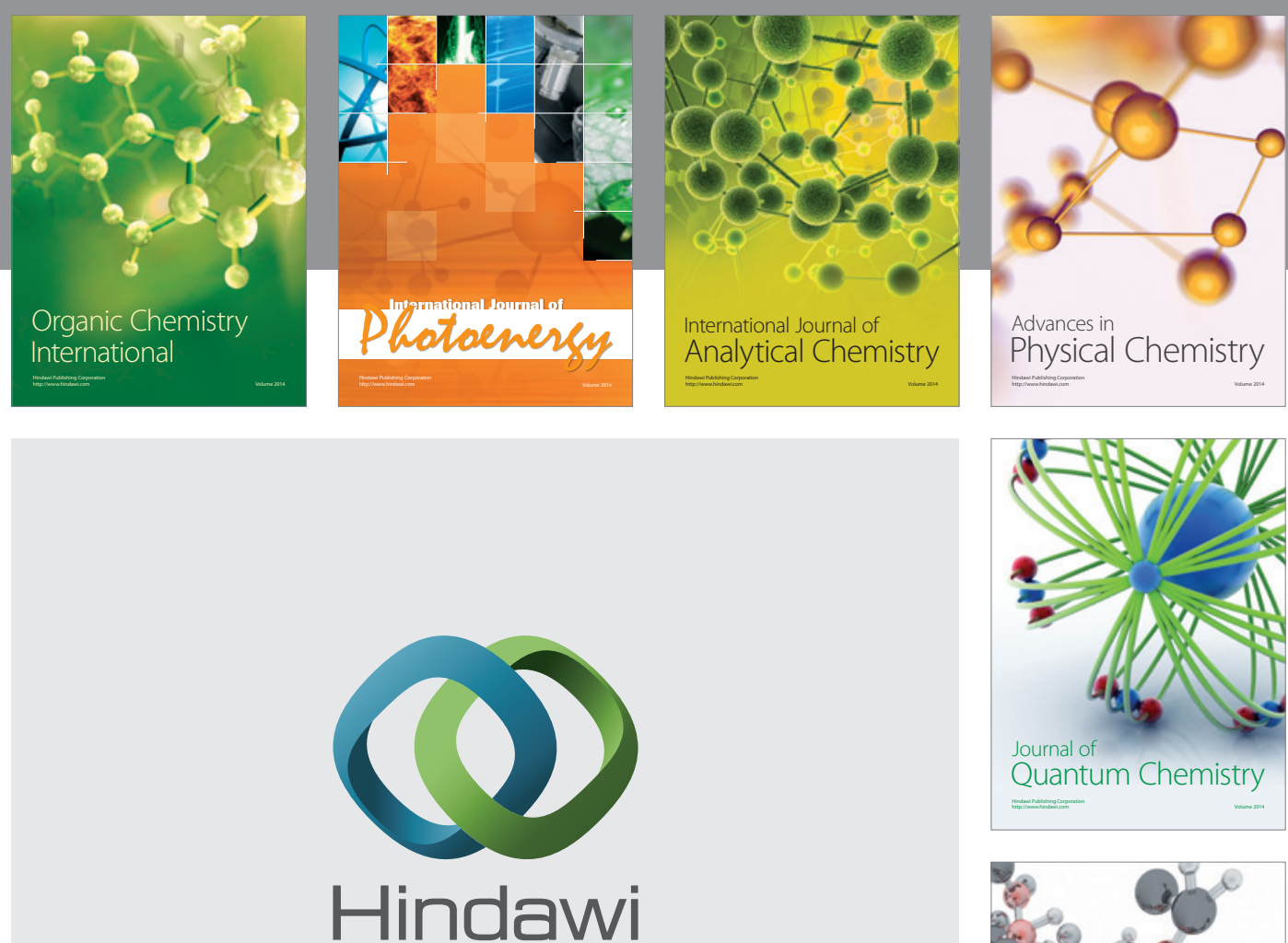

Submit your manuscripts at

http://www.hindawi.com

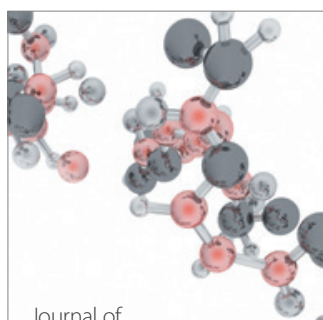

Analytical Methods

in Chemistry

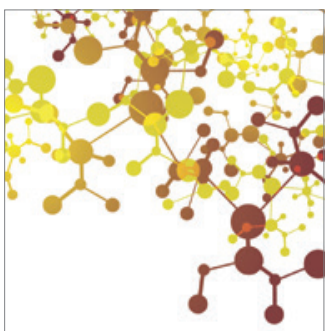

Journal of

Applied Chemistry

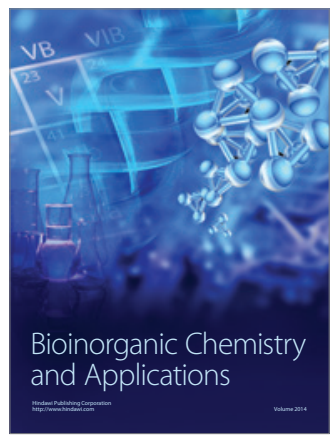

Inorganic Chemistry
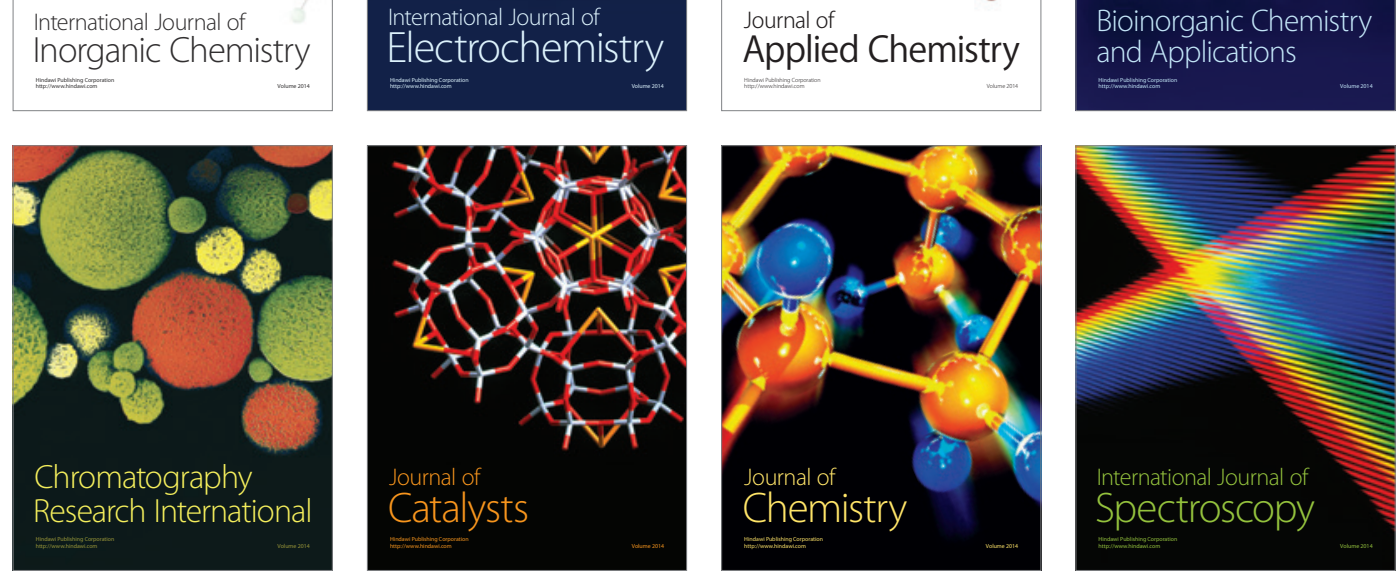